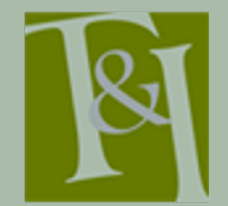

The International Journal for Translation \& Interpreting Research trans-int.org

\title{
Trainee translators' research styles: taxonomy based on an observation study at the University of Silesia, Poland
}

\author{
Joanna Ewa Sycz-Opoń \\ University of Silesia, Poland \\ joanna.sycz@us.edu.pl
}

DOI: 10.12807/ti.113202.2021.a08

\begin{abstract}
This paper presents a typology of information-seeking styles exhibited by 52 students of the MA translation and interpreting programme at the University of Silesia, Poland. The typology emerged during the large-scale investigation into trainee translators' research behaviour occurring during translation of a legal text from English into Polish (Sycz-Opoń 2019). The method of investigation combined observation of students' recorded performances with a think-aloud protocol (TAP). The case-study analysis brought to light significant variation in student's informationseeking behaviour, which had gone unnoticed in the aggregate statistical data. Individual differences included students' source preference, search intensity, level of criticism towards sources, diligence, risk-taking, self-confidence, and source reliance. As a result of the analysis the six research styles emerged: traditionalist, innovator, minimalist, true detective, procrastinator, and habitual doubter. They are presented in this paper with special attention to each style's strengths, weaknesses and recommended teaching approaches. The results suggest the need for informationseeking training geared towards the diverse needs of individual students.
\end{abstract}

Keywords: Information-seeking behaviour; research behaviour; translator's instrumental competence; translator's resourcing skills; legal translation; research styles.

\section{Introduction}

This paper presents the six different research styles ${ }^{1}$ exhibited by the students in a postgraduate translation and interpreting programme at the University of Silesia, Poland, during the English to Polish translation of a legal text. The typology of the research styles emerged during a linear, case-study analysis of each participant's information-seeking behaviour ${ }^{2}$, as part of a larger research project investigating this topic from a statistical perspective (Sycz-Opoń, 2019). The analysis of case studies brought to light significant variation in research behaviour of the participants. It turned out that the group under scrutiny was far from homogenous: the participants differed, inter alia, in their source preferences, search intensity, level of criticism towards sources, diligence, and source reliance. Thus, this paper complements Sycz-Opoń's (2019) discussion by adding a more idiographic approach. While the statistical analysis in SyczOpoń (2019) focused on information-seeking behaviours characteristic for the majority of students, presenting common behaviour patterns, shared

\footnotetext{
${ }^{1}$ Style, following Zhang \& Sternberg (2005:2), is understood here as "one's preferred way of processing information and dealing with tasks."

${ }^{2}$ Also termed information-mining behaviour, consultation behaviour, source use or research behaviour. It is understood as any behaviour related to active search for information in external sources, and is a subcategory of information behaviour which additionally includes information encounter, passive reception of information, or purposeful avoidance of unwanted information.
} 
preferences, struggles and dilemmas, this study investigates the traits on which the participants varied. The result of the analysis is the classification of six research styles exhibited by translation students, namely: traditionalist, innovator, minimalist, true detective, procrastinator, and habitual doubter, which are described here with special attention given to each style's strengths and weaknesses, as well as teaching recommendations for translator educators.

The results of this study might find application in the education of future translators. Even though information literacy is now recognized as one of the key translator's competencies - included in major translation models, e.g., by PACTE (2005, 2017), EMT Expert Group (2017), NAATI (n.d.) and ISO 17100:2015 norm (2015) - still very little is known as to how research competence could be effectively developed during translator training. This paper contributes to the field by providing information on a rarely discussed aspect of translators' education - individual differences, which as far as mining for information is concerned, turned out to be quite significant in the study reported on here.

In general, variations in information-seeking behaviours exhibited by individuals may be related to several factors:

1. First of all, participants' knowledge and experience with sources of information. The tested sample consisted of students who had not attended any specific course devoted to translators' instrumental competence $^{3}$. Having no formal systematic education in this area, each student had acquired information-seeking strategies on their own through individual interaction with sources of information (with greater or lesser success depending on their personal interest in the subject), access to sources, and their general IT skills.

2. Secondly, individual cognitive skills and intellectual styles ${ }^{4}$, including such mental processes as perception, attention, memory, creativity, knowledge acquisition and retention, logical reasoning, problem solving, and decision making. As Tarp (2007, p.172) explains, "dictionaries themselves do not contain information, but only lexicographically selected and prepared data from which the users may or may not be able to retrieve the needed information." Thus, "data [found in a source] may or may not be information depending upon the state of understanding of the information user" (Wilson, 2000, p. 50).

3. Individual personality traits, investigated by Jung (1923), Allport \& Odbert (1936), Murray (1938), Cattell (1943), and Eysenck (1947), to name just a few. The latest personality model - $\mathrm{HEXACO}^{5}$ (an updated version of the Big Five) distinguishes six personality dimensions: honesty-humility, emotionality, extraversion, agreeableness/anger, conscientiousness, and openness to experience (Lee \& Ashton, 2018). Unique combinations of personality traits influence the way people perceive the outside world, respond to situations and interact with others, even during activities apparently perceived as rational or mechanical, including information seeking (Ford, 1986; Heinstrom, 2003, 2005, 2010; Tidwell \& Sias, 2005) and translation (Hubscher-Davidson, 2009; Lehka-Paul \& Whyatt, 2016).

\footnotetext{
${ }^{3}$ As defined in the PACTE model (Beeby et al., 2005, p.610) instrumental competence includes "knowledge related to the use of documentation sources and information technologies applied to translation". In other models it is referred to as information-mining competence (EMT Expert Group,2017), research competency (NAATI, n.d.), and competence in research, information acquisition, and processing (ISO 17100:2015).

${ }^{4}$ A term coined by Zhang \& Sternberg (2005) to be used as an umbrella term embracing all cognitive styles, e.g. reading, writing, thinking, and learning styles.

${ }^{5}$ The acronym HEXACO stands for the first letters of the six personality dimensions the model investigates: Honesty-humility, Emotionality, eXtraversion, Agreeableness, Conscientiousness, and Openness to experience.
} 


\section{Previous studies}

The study reported on here locates itself in the line of research into individual differences and draws on two scholarly traditions: information science and translation studies. In information science, one of the first scholars investigating individual differences in how people look for information was Nigel Ford (1979). Other scholars contributing to this field include Allen \& Kim (2001), Heinström $(2005,2006)$, Halder et al. (2010), and Pedrazzini \& Nava (2012) . Yet, despite the fact that, as Bawden \& Robinson (2011, p. 282) note, the topic "has been discussed in literature for at least four decades", it still remains on the periphery of information behaviour studies, with the majority of investigations taking the statistical nomothetic approach ${ }^{7}$ aimed to reveal general, broadlyapplicable principles.

In the field of translation studies, translators' research behaviour is still a relatively new area of study, with practically all investigations presenting generic data (e.g., by Cui \& Zheng, 2020; Désilets et al., 2009; Enríquez Raído, 2014; Gough, 2017; Hirci, 2013; Hvelplund, 2017, 2019; Massey \& Ehrensberger-Dow, 2011; Muller-Spitzer et al., 2012; Olalla-Soler, 2018; Pinto \& Sales, 2007, 2008; Pinto et al., 2014; Sales \& Pinto, 2011; Shih, 2019; White et al., 2008; Zapata, 2016;). Some references to individual differences can be found in the studies investigating translation process (e.g., by Carl et al., 2011a; Dragsted \& Carl, 2013; Heinstrom, 2003; Huang, 2018; Hubscher-Davidson, 2009; Lehka-Paul \& Whyatt, 2016; Tirkkonen-Condit, 2005). However, it should be stressed that the focus of these studies is on other aspects of the process of translation, with minimal interest in translator aids or deliberate elimination of source consultation from the scope of investigation, as in the studies by Carl et al. (2011a, 2011b) and Dragsted and Carl (2013). To the best of my knowledge, only three studies have referred to individual differences in translators' information-seeking behaviour to date, namely those by House (2000), Enríquez Raído (2011) and Gough (2016), which leaves much room for further investigations.

\section{Methodology}

The methodology applied in this study combines two methodological tools: direct observation, and think-aloud protocol (TAP). The study involved the participation of 104 translation students, aged 24 to 26, both male and female, native speakers of Polish, with English as their second language. At the time of the study, they were in the first and second year of the MA translation programme at the University of Silesia, Poland. Their general competence in the English language could be assessed as level $\mathrm{C} 1 / \mathrm{C} 2$ in The Common European Framework of Reference for Languages scale, and they had basic translation skills acquired during their studies $(90-150 \mathrm{~h}$ of translation classes completed before the experiment session). They had not attended any practical course aimed specifically at information literacy, yet during the translation classes preceding the experiment the students had been briefly introduced to various sources of information.

The recording/observation session took place in the university's computer room. The participating students were divided into pairs and assigned the roles of Translator and Recorder.

- Translators were asked to translate a legal text with the assistance of available sources. They were also expected to think aloud - explain

\footnotetext{
${ }^{6}$ More studies can be found in an overview by O'Brien et al. (2017).

7 Too many to attempt citation here; an extensive overview of the studies can be found in Case (2016).
} 
their choices and decisions and comment on the quality of consulted sources when asked by the Recorders.

- $\quad$ Recorders were tasked with recording every move of the Translators related to the consultation process, as well as their spontaneously expressed comments on the Observation Protocols (see Appendix 1). The Recorders were also expected to record search results and the Translators' level of satisfaction. The Recorders were asked to elicit comments from the Translators and were free to write down their own comments related to the Translator's behaviour, based on their observations.

Additionally, the participants' computer activities and conversations were recorded by means of a screen-capture and sound-recording tool. The translation assignment consisted of paragraphs taken from a book on English court translation (Berezowski, 2011), with some passages added to make the text more demanding for the students, thus requiring consultation of a range of sources. Each recording/observation session was conducted during a single university class: 10 minutes were spent explaining the procedure and 1 hour and 20 minutes on the task itself. The translation task was performed with the use of Microsoft Word software. Participants had unlimited access to the internet and could also consult major lexicographical publications available at that time on the Polish market - obtained from the University's library and from participants' private resources ${ }^{8}$. Each participant had at his/her disposal at least one source representing the following categories: monolingual general dictionary, bilingual general dictionary, bilingual legal dictionary, monolingual legal dictionary or encyclopaedia of law, and publicly available parallel texts e.g., translations of legal acts including the Polish Civil Code by Kierzkowska et al., 1997, and the European Union's multilingual online law repository (EURLex, n.d.) - in a printed ${ }^{9}$ or digital form.

\subsection{Data analysis}

The data analysis combined a quantitative and qualitative approach. The first stage of the analysis was the examination of data retrieved from the Observation Protocols, namely:

- $\quad$ source preference (frequency of look-ups in various types of sources) - retrieved from Section 2 of the Protocols,

- reasons for source preference - Section 3 of the Protocols,

- information sought by the participants (equivalent, definition, collocation, etc.) - Section 4,

- $\quad$ satisfaction with look-up results - Section 5,

- reasons for dissatisfaction or partial satisfaction with look-up results, which provided information on repeatedly encountered problems Section 5,

- $\quad$ search intensity (average number of look-ups per search) - entire Protocols ${ }^{10}$.

\footnotetext{
${ }^{8}$ Since the aim of the study was to capture natural information-seeking behaviour (as far as it was technically possible in the classroom setting of the session) the participants were allowed to bring their own dictionaries or other publications of any kind that might in their opinion help them during translation. They could share their sources with other participants. Some of them indeed used that opportunity and brought a legal translation textbook by Jopek-Bosiacka (2006) recommended to them during the introductory translation classes at the beginning of the semester. ${ }^{9}$ Several LSP lexicographical publications are available only in printed format on the Polish lexicographical market.

${ }^{10}$ The Recorders were asked to write down the item being researched by the Translator in Section 1 of the Observation Protocol. Then they were to write down each consulted source in a separate row (each row is devoted to a single source being consulted) in Section 2 of the Observation Protocol (leaving Section 1 empty). The sources were recorded in chronological order (i.e. the order in which they were consulted by the Translator).
} 
The statistical data were first obtained for each participant individually, and then the average was made for the whole group. This method made it possible to see discrepancies between the students participating in the study (the selected graphs - relevant in the context of this discussion - are presented in Appendices 2 to 11; they present the scores of each of the 51 subjects).

The second stage of the analysis was the examination of audio and video recordings. The information-seeking behaviour of each participant was analysed linearly (from the moment of identifying an information need to the moment of concluding a particular search) and holistically (taking into consideration various aspects) in order to discover common information paths and other characteristics of subjects' research behaviour, such as:

- depth of search within the source (e.g., reading the whole dictionary entry vs. just the first lines, or reading many example sentences in a parallel text repository vs. just the top ones),

- the tendency to verify information found in a source,

- $\quad$ source-reliance vs. self-reliance,

- level of technological literacy (use of advanced search options),

- level of lexicographic literacy (ability to quickly locate information in a traditional dictionary, knowledge of dictionaries' macro and microstructure),

- characteristic search paths.

During the analysis of case studies, one could observe certain correlated characteristics, exhibited by only a portion of the entire tested group, which were impossible to spot in the aggregate statistical data. The participants were clustered into types according to shared aspects of their information-seeking behaviour. The analysis revealed that they differed most in the following areas:

- $\quad$ source preference

- risk-taking

- $\quad$ source-reliance vs. self-confidence

- conscientiousness

- $\quad$ search systematicity

- uncertainty level

The combinations of these differences formed the basis of the research styles presented below. Each type is created according to the main characteristic feature accompanied by other complementary traits. The types presented below are naturally prototypes. The majority of participants lean toward one or two of these categories, with only a few participants being pure examples of a given style.

\section{Trainee translators' research styles}

\subsection{Traditionalists}

Traditionalists mostly use dictionaries. Even though they prefer lexicographical tools in a modern format (desktop or online), they are also willing to use printed sources if necessary ${ }^{11}$. They seem to be experienced dictionary users (they navigated dictionary entries with ease and exhibited knowledge of their structure and content), yet are not familiar with alternative sources of information (sources other than dictionaries were rarely consulted). Traditionalists appear to be late adopters of new technologies. They seem to consult traditional dictionaries not because they value their reliability (this was not expressed in their comments), but due to limited familiarity with alternative sources of information. They are lost in a situation in which dictionaries fail to provide them with the required information. Their conservative approach might

${ }^{11}$ Several high-quality LSP dictionaries are available only in a printed format on the Polish market. 
be attributed to generally low IT literacy or limited openness to novelty.

\subsubsection{Illustrative case studies - traditionalists:}

Participant JK consulted mostly printed legal dictionaries and one electronic collaborative dictionary: ling.pl. Besides dictionaries, she also sought help in printed textbooks: Lexicon of Law Terms by Myrczek-Kadłubicka (2013b) and Przektad prawny i sadowy by Jopek-Bosiacka (2006), as well as the MT tool translatica.pl, which she treated as a standard dictionary - she checked single words. Printed sources constituted 60 per cent of all consulted sources.

Participant AW used almost exclusively bilingual dictionaries: both printed legal dictionaries and general online dictionaries, with only a few lookups in proz.com. This participant also looked up definitions of several legal terms in online monolingual legal dictionaries. Printed sources constituted 59.38 per cent of all consulted sources.

Table 1. Characteristics - traditionalists

\begin{tabular}{|l|l|}
\hline \multicolumn{1}{|c|}{ Strengths } & \multicolumn{1}{c|}{ Weaknesses } \\
\hline - $\begin{array}{l}\text { efficient navigation within traditional } \\
\text { dictionaries }\end{array}$ & $\begin{array}{l}\text { - insufficient knowledge about the sources } \\
\text { of information other than dictionaries }\end{array}$ \\
- knowledge of dictionaries' macro and \\
$\begin{array}{l}\text { microstructure } \\
\text { willingness to use printed sources if } \\
\text { necessary }\end{array}$ & $\begin{array}{l}\text { lownological literacy } \\
\text { preference for sticking with familiar } \\
\text { routine } \\
\text { insufficient internal motivation to check } \\
\text { out new sources or search techniques }\end{array}$ \\
\hline
\end{tabular}

\subsubsection{Teaching recommendations:}

- In general, use of official lexicographical publications is to be praised, yet it might be a source of problems for traditionalists, when it is not accompanied by the efficient use of alternative sources to obtain information not provided in dictionaries.

- The instruction addressed to traditionalists should focus on the benefits arising from the use of non-traditional sources of information (ability to find additional information, not included in traditional dictionaries, e.g., context of use, grammatical attributes, collocations, or meaning of a given term).

- Since the reason for traditionalists' reluctance to use new sources might be their low IT literacy, part of the course should be devoted to technical aspects of source consultation, accompanied by practical exercises, preferably in the classroom, so that traditionalists can use their teacher's or classmates' assistance.

\subsection{Digital natives}

Digital natives exhibit a strong preference for electronic sources, such as online collaborative dictionaries, internet forums, MT tools, and online text corpora (these sources were consulted by them most often). At the same time, they have a distinctively negative attitude towards printed sources (expressed in comments) and feel incompetent at using them (several participants even reported problems with the alphabet when looking up entries in printed dictionaries), presumably due to limited experience. They navigated online sources with ease and speed, and were much more familiar with them than Traditionalists. They preferred searching for an answer in numerous internet sources rather than reaching for a specialised printed dictionary. It appears that they do not realise the difference between an official lexicographical publication and an online glossary, and thus do not want to invest extra time and effort in consultation of a traditional source available in a printed format. 


\subsubsection{Illustrative case studies - digital natives:}

Participant ELG used mostly Google search engine, bab.la online dictionary, and Wikipedia. She usually started her search with the consultation of the online dictionary bab.la, which in the majority of cases provided satisfactory results. When this participant felt the need for further information, she used Google search engine and checked where it would lead her. Occasionally, she reached for printed bilingual dictionaries by Ożga (2009) and Myrczek-Kadłubicka (2013a).

Participant TR consulted online sources, such as Glosbe, Wikipedia, translatica.pl, diki.pl, proz.com, thefreedictionary.com, and desktop general dictionaries such as The New English-Polish and Polish-English Kościuszko Foundation Dictionary (Fisiak, 2005), a legal desktop dictionary by Jaślan \& Jaślan (2007), and webpages suggested by Google. There were only two lookups in the printed bilingual legal dictionary by Myrczek-Kadłubicka (2013a). Many of her look-ups were marked as unsatisfactory. In such cases, the participant decided not to continue the search and attempted translation.

Table 2. Characteristics - digital natives

\begin{tabular}{|l|l|}
\hline \multicolumn{1}{|c|}{ Strengths } & \multicolumn{1}{|c|}{ Weaknesses } \\
\hline - technological literacy & $\begin{array}{l}\text { - insufficient knowledge of traditional } \\
\text { dictionaries' structure and content }\end{array}$ \\
$\begin{array}{l}\text { - openness to new sources of information } \\
\text { - capacity to effectively adapt to new } \\
\text { information reality }\end{array}$ & $\begin{array}{l}\text { reluctance to use printed sources } \\
\text { when necessary } \\
\text { - willingness to try new approaches }\end{array}$ \\
\hline
\end{tabular}

\subsubsection{Teaching recommendations - digital natives:}

- Teacher intervention should focus on motivating digital natives to use traditional lexicographical sources, including printed ones, in justified cases.

- During classroom and face-to-face discussions with digital natives, the teacher should highlight the advantages of dictionaries, e.g., wellselected equivalents, verified specialist content, recognised expert author, and lack of irrelevant information - which in practice might result in shorter search time, even when a lexicographical source in a printed format is consulted.

- At the same time, the focus should be placed on the quality of sources and their reliability, so that digital natives fully understand the risks involved in the consultation of sources whose content is unverified, such as online collaborative dictionaries, random forums or blogs.

- The students should be provided with practical guidance regarding how to verify the reliability of a source.

- Finally, to make students acknowledge the difference between a random no-name online glossary and a published dictionary, part of the course might be devoted to presentation of the complexities of lexicographical work (how lexicographical sources are compiled), preferably with classroom lexicographical practice.

\subsection{Minimalists}

Minimalists' information-seeking behaviour is characterized by a low consultation rate (usually one or two look-ups per search). They treat consultation of sources as a last resort and prefer to rely on their knowledge and 
experience. The observation revealed that they are not afraid to create their own renditions of terms or phrases if they find no matching equivalent in sources. During source look-up, they scan the content of sources hastily and with impatience. They choose sources that are easily accessible and provide information fast. They seem not to be much concerned about the reliability or correctness of the information found, compared to other students. They are content with every equivalent found in whatever source as long as it matches the context. Thus, they usually go with the first equivalent, found in an easily accessible source. Since they obtain a minimal amount of information from sources, they run the risk of making translation decisions based on insufficient grounds.

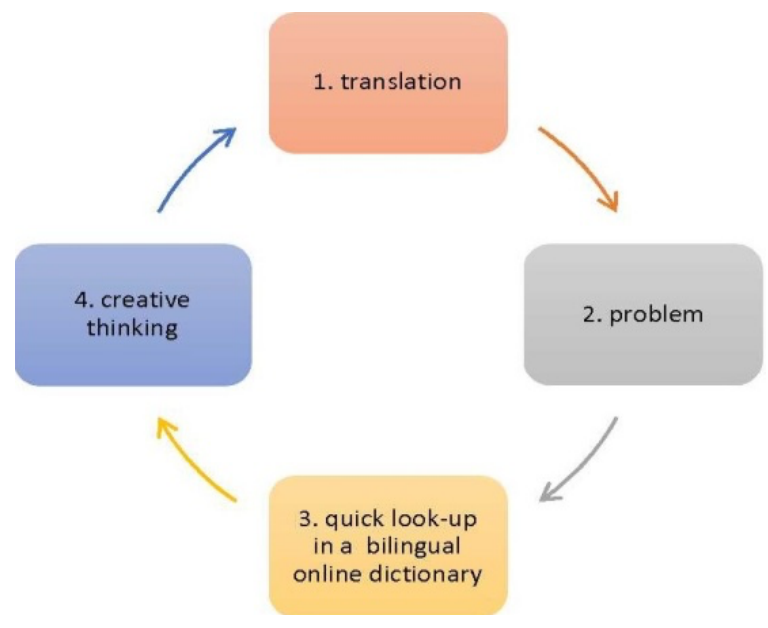

Figure 1. Typical information path of minimalists

\subsubsection{Illustrative case studies - minimalists:}

Participant PK relied almost entirely on his translation skills and knowledge during translation. His total number of searches and look-ups equalled 14, which means that each search consisted of only one look-up. Legal terms were checked in printed bilingual dictionaries, while general terms were sought in online bilingual dictionaries.

Participant GD performed 24 look-ups and 22 searches. Only two searches consisted of two look-ups: the search for wherefore (the general online dictionary megaslownik.pl provided an unsatisfactory result and proz.com a satisfactory one) and the search for the phrase I believe that the facts stated in this complaint are true. The phrase was typed into Google search box, but Google generated only English results, so then the phrase was verified in proz.com, with a partially satisfactory result, because only some elements of the phrase were found. The participant decided to use these elements to produce her own rendition of the phraseme. The rest of the searches consisted of one lookup. Single words were consulted in bilingual computer dictionaries and phrases in proz.com or Google search engine. Most of them were marked as satisfactory.

Table 3. Characteristics - minimalists

\begin{tabular}{|c|c|}
\hline Strengths & Weaknesses \\
\hline $\begin{array}{l}\text { - independence and self-reliance } \\
\text { - self-confidence } \\
\text { - creativity } \\
\text { - decisiveness } \\
\text { - speed and efficiency }\end{array}$ & $\begin{array}{l}\text { - tendency for cursory search } \\
\text { - shallow analysis of the content offered by } \\
\text { the sources } \\
\text { - impatience } \\
\text { - insufficiently critical approach towards the } \\
\text { sources of information }\end{array}$ \\
\hline
\end{tabular}




\subsubsection{Teaching recommendations - minimalists:}

- Since minimalists undervalue the role of sources in translators' practice, teachers' intervention should focus on highlighting what benefits the consultation of sources can bring. During classroom and face-to-face discussions with minimalists, the teacher should highlight the need for in-depth research and the double-checking of information found, in justified cases.

- Secondly, the teacher's role is to develop students' critical attitude towards their own ideas and external sources. Discussions with minimalists should focus on the risks related to lack of consultation or hasty consultation of easily accessible sources (e.g., selecting the equivalent of a term that does not fit into a given context), preferably with practical examples.

- Finally, minimalists should be provided with practical guidance regarding how to 'read' the content of the sources, e.g., to pay attention to the context of use of a given term or its grammatical attributes, to read numerous example sentences in text corpora (not just the top one), etc.

\subsection{True detectives}

True detectives' information-seeking behaviour is characterised by numerous look-ups per search and in-depth reading of source content. Though long, the searches are often ineffective, because of the lack of a well-thought-out search strategy. The common mistakes include looking up only bilingual sources or searching inaccurate multi-word clusters (which do not constitute established phrasemes). When faced with incomplete information in a source, true detectives continue their search in other available sources, usually other bilingual dictionaries. Since their expectations towards the sources are high, they often express a low level of satisfaction with look-up results. True detectives are over-reliant on the sources of information. Their behaviour suggest that they expect to find information that would relieve them of the responsibility for making their own translation decisions, probably because of insufficient confidence in their own translation skills and unwillingness to take risks. Some true detectives devoted more time to seeking information than to actually translating the text.

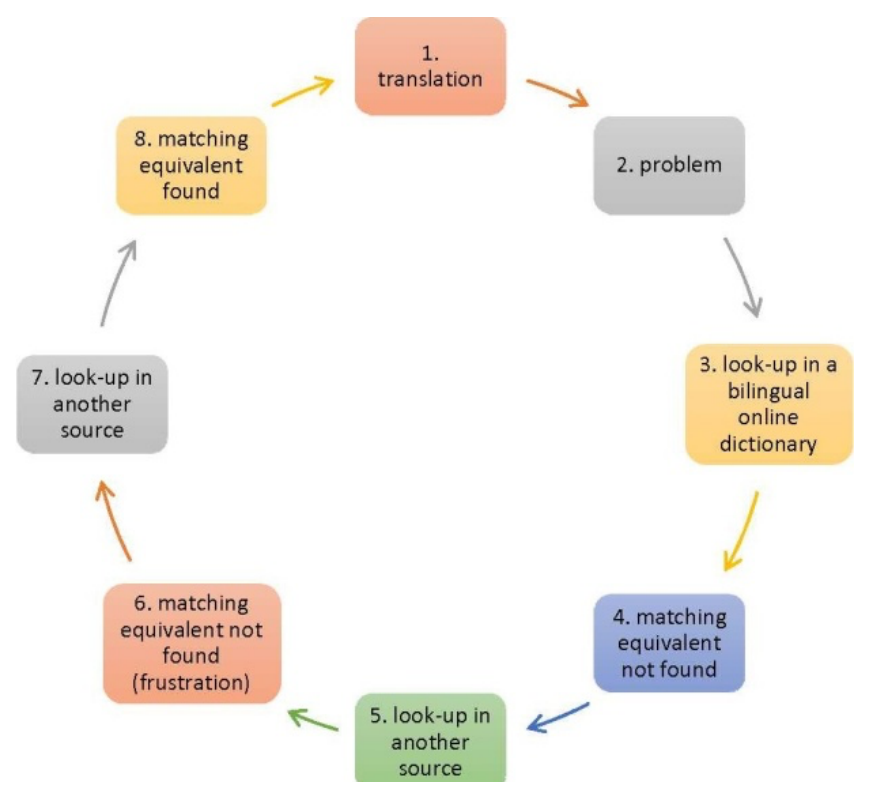

Figure 2. Typical information path of true detectives 
4.4.1 Illustrative case studies - true detectives:

Out of the 38 searches performed by Participant ASK, only 15 consisted of single look-ups. The remaining searches included two to eight look-ups. The longest was the search for the term complaint, with eight look-ups in the following sources: a bilingual legal dictionary by Ożga (2009), a bilingual legal dictionary by Jaślan and Jaślan (2007), Kościuszko Foundation Dictionary (Fisiak, 2005), Google search engine, Polish Civil Code, again the dictionary by Ożga (2009), and again the dictionary by Jaślan and Jaślan (2007).

Another true detective was Participant MR, who performed 64 look-ups in 28 searches. One of his searches involved the expression in no manner or respect. First, he typed the whole phrase in Google search box, yet without inverted commas. Since the results were not satisfactory, he typed a shortened version, this time with inverted commas: manner or respect, which generated even more abstract results (e.g., girls who speak with no manner or respect). Then he consulted proz.com, yet it produced no results with this word combination. The participant tried further, using Google MT, and obtained a nonsense translation (nie sposób lub szacunek ${ }^{12}$ ), which actually distanced him from the proper answer. Finally, he decided to disregard the worthless search results and used his common sense plus contextual information to translate the sentence as $w \dot{z}$ adnym wypadku (which is a correct rendering of the phrase).

Table 4. Characteristics - true detectives

\begin{tabular}{|l|l|}
\hline \multicolumn{1}{|c|}{ Strengths } & \multicolumn{1}{c|}{ Weaknesses } \\
\hline - tirelessness and patience & - slow pace of translation \\
- curiosity & - over-reliance on reference material \\
- perfectionism & - low self-confidence \\
- conscientiousness and attention to detail & - low creativity \\
& - ill-conceived search strategy \\
\hline
\end{tabular}

\subsubsection{Teaching recommendations - true detectives:}

- The main problem for true detectives, in their future professional work, will probably be meeting deadlines and time pressure. Thus, to make the students develop time management skills, time discipline should be introduced into the classroom, e.g., by setting time limits for completion of a translation assignment.

- Moreover, the teacher should encourage true detectives to rely more on their translation skills than on equivalents offered by sources. True detectives need to understand the role of sources in translators' practice - dictionaries are not to provide ready-made solutions; they provide the translators with bits of information that help them come up with the required solutions on their own.

- The students should also receive practical guidance regarding how to use incomplete information found in sources when working on a translation, preferably accompanied by classroom practice.

\subsection{Habitual doubters}

Habitual doubters' research behaviour is characterised by a high consultation rate, motivated by the need to confirm information or their own ideas. Habitual doubters, unlike minimalists, are anxious about the quality of the information found. Having no expert knowledge of the subject matter, they have no choice but to verify the information in another source. Habitual doubters are suspicious towards the majority of sources, even the ones that are generally perceived as reliable (e.g., officially published legal dictionaries) and their own knowledge.

${ }^{12}$ Literal translation: not way or respect 
Uncertainty about the information offered by sources may be attributed to the fact that the students do not know the sources very well. They have limited experience with the sources, thus they have not built trust towards them. Habitual doubters' need to double-check the information offered by sources could also be attributed to their personality traits, such as general unwillingness to take risks and a comparatively high level of anxiety, which as the research by Kuhlthau (1993) revealed, is experienced by most information seekers to some extent.

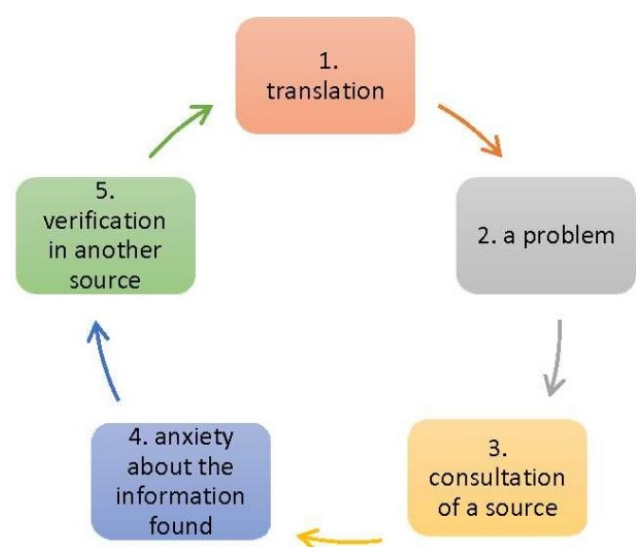

Figure 3. Typical information path of habitual doubters

\subsubsection{Illustrative case studies - habitual doubters}

Participant MW sought confirmation of information 24 times. The number of look-ups conducted by him was 53 and the number of searches was 33. The second look-up in almost all searches conducted by him was aimed at confirmation of the information found in the first source. For example, he verified the equivalent of the term complaint found in proz.com in three other sources: ling.pl and Google search engine, which directed him to the online monolingual dictionary freedictionary.com. He also tended to confirm his own knowledge in sources, e.g., with regard to the terms executive, division, pursuant to.

Participant JM double-checked most information found in sources. He verified the contents of officially published dictionaries and online sources with equal eagerness. For example, he found two equivalents of the term allege in a desktop legal dictionary (Jaślan \& Jaślan, 1994) and felt that he needed to make sure that the equivalent chosen by him was correct; he verified it by looking at the context of use in Google search engine. He also checked his own knowledge. For example, he consulted Jaślan \& Jaślan (2007) to make sure that he remembered correctly the equivalent of breach.

Table 5. Characteristics - habitual doubters

\begin{tabular}{|c|c|}
\hline Strengths & We \\
\hline $\begin{array}{l}\text { - conscientiousness } \\
\text { - patience } \\
\text { - critical approach to the sources of } \\
\text { information }\end{array}$ & $\begin{array}{l}\text { - slow pace of translation } \\
\text { - high level of anxiety } \\
\text { - ineffective methods of critical assessment } \\
\text { of the information found in sources }\end{array}$ \\
\hline
\end{tabular}

\subsubsection{Teaching recommendations - habitual doubters:}

- The teacher's intervention should focus on building students' selfconfidence and trust in the sources by means of reflective practice (conscious use of a variety of sources during translation, accompanied 
by classroom discussion directed at the quality of the obtained search results).

- Habitual doubters should be presented with efficient methods of information verification and confirmation.

- Like true detectives, habitual doubters might have problems with meeting deadlines, and thus might require time discipline during translation assignments, so that they can develop time management skills.

\subsection{Procrastinators}

Most students perform translation in a way that could be described as linear. They translate the text until they encounter a linguistic problem, then they solve the problem and move on with their translation. Procrastinators exhibit a different pattern: when they cannot solve a problem, they leave it unsolved. They keep it at the back of their minds, and when they acquire new information or see the same lexeme in a different context, they make further attempts to solve the unresolved dilemma. Such a method can be very useful, since it allows the translator to look holistically at the translated text and look for clues in further parts of the text, which should lead to better renditions of terms. On the other hand, if it serves as a means of escape from translation difficulties, it may lead to the accumulation of translation problems at the end of a translation task.



Figure 4. Typical information path of procrastinators

\subsubsection{Illustrative case studies - procrastinators}

Participant MW had problems with translation of the term repudiation. The first search for the term consisted of two look-ups: in ling.pl and proz.com. It was marked as satisfactory. As he continued translation, the participant realized that the term had been rendered wrongly, so he checked the term in ling.pl (again), in proz.com (again) and in a bilingual legal dictionary by Myrczek-Kadlubicka (2013a). This time, the search was classified as partly satisfactory. After a while, he returned to the term again, checking its meaning in Wikipedia. He decided to look for the word cluster breach and repudiation in proz.com and Google search engine. There were no valid results in proz.com, but Google provided a satisfactory answer. In total, the search for repudiation involved eight look-ups and three search sessions.

Participant DSZ postponed translating many terms: repudiation, thereto, hedonic, claimant, service of process, and thereto. Repudiation, claimant and thereto were first looked up in a desktop legal dictionary by Jaślan \& Jaślan (2007) and the search results were marked as satisfactory. These three terms were looked up again later on as they appeared in the text in different contexts. 
The participant wanted to double-check the correctness of his translation of these terms or forgot that he had checked them before. Hedonic was looked up in dictionaries by Jaślan \& Jaślan (2007), Myrczek-Kadłubicka (2013a), and Collin \& Stupski (1999). The search was marked as partly satisfactory. The participant decided not to translate the term. There was no time left for resuming the search. Thus, the word remained untranslated.

Table 6. Characteristics - procrastinators

\begin{tabular}{|l|l|}
\hline \multicolumn{1}{|c|}{ Strengths } & \multicolumn{1}{c|}{ Weaknesses } \\
\hline - ability to connect facts & - indecisiveness \\
- holistic approach to translated texts & - giving up too soon \\
- ability to use contextual information within & - impatience \\
a text to solve translation problems & - possible problems with meeting deadlines \\
\hline
\end{tabular}

\subsubsection{Teaching recommendations - procrastinators:}

- The teacher's intervention should focus on tackling procrastination and 'escapism', and at the same time, develop students' decisiveness and work efficiency.

- The classes' organization should encourage individual work, so that procrastinators are motivated to face difficulties on their own, rather than waiting for the teacher or classmates to provide the solution to a problem.

- Focus should also be placed on better work organization and time management skills, in the case of students who have problems with meeting deadlines.

\section{Conclusion}

The majority of studies on information behaviour present statistical data that highlight general trends and provide universal solutions. The tested sample is often juxtaposed with other occupations, age groups, or more/less experienced peers to reveal intergroup differences. This strengthens the impression that the group under scrutiny in a given study is to a large extent uniform. The results of this investigation suggest the contrary. It appears that students adapt to technological changes at a varied pace, presumably due to their cognitive predispositions as well as environmental factors. Moreover, in the study it could be observed that they differed in their inclination to take risks, level of selfconfidence, conscientiousness, curiosity, impatience, criticism, and knowledge - all of which shape their information behaviour.

The results of this study should be taken with caution due to its limitations (participants from one educational institution, translation of a single genre from L2 to L1 only). The typology presented above is also an inevitable simplification, since it considers only the most visible differences between the participants. Moreover, taking into account the fast-changing information environment - new technological tools being introduced and existing ones being enhanced - it could be expected that translators' information behaviour will somehow evolve. New information-seeking styles will probably emerge, and the ones described here might change, as the students (and publishing houses offering lexicographical publications) further embrace online technological solutions. However, what will probably remain constant is intragroup variation, which needs to be recognised in a pedagogical context.

If we aim to develop a well-designed course that matches the educational needs of all students, we should take into account this within-group diversity. The realisation that a group is not homogenous can help the teachers personalise 
their approach to individuals and create a teaching programme that caters for students' diverse needs. How such a course should look is a topic for a separate discussion and for future empirical studies. However, some suggestions can be made now. First, the differences between the students could be levelled out by means of their controlled arrangement in a classroom. If representatives of various types were located close to each other and asked to cooperate during various group activities, they could observe each other, share their skills and exchange views, and in this way discover other information-seeking strategies. Another idea could be a self-discovery survey (which type of researcher are you?) which would give students a chance for self-reflection. Such a survey would, first of all, draw students' attention to this aspect of their translation performance. Moreover, the realization that one is a representative of a given type would be a good starting point for strategic self-development. Such a survey would also provide teachers with information: representatives of which styles, and in what proportions, attend their course. Thirdly, the teacher could apply personalised homework assignments - aimed at development of these aspects of information literacy that a given student struggles with. For example, a digital native might be asked to use only dictionaries while working on the next translation, and a traditionalist - to use all the sources except dictionaries. A minimalist might be asked to increase their use of sources, and a true detective - to attempt translation without the assistance of any source.

On a more general level, the results of this observation study as well as other studies into individual differences suggest that students would benefit more from a mentor-apprentice model of teaching, than from standard group classes. For economic reasons, education based solely on tutoring is hardly attainable. Yet as much as it is practically possible, we should aim at smallgroup translation courses, which can give the teacher the opportunity to provide the students with personalised feedback and teaching approach adjusted to their individual educational needs.

\section{References}

Allen, B., \& Kim, K.-S. (2001). Person and context in information seeking: Interactions between cognitive and task variables. The New Review of Information Behaviour Research, 2(November), 1-16.

Allport, G. W., \& Odbert, H. S. (1936). Trait-names: A psycho-lexical study. Psychological Monographs, 47(1).

Bawden, D., \& Robinson, L. (2011). Individual differences in information-related behaviour: What do we know about information styles. In A. Spink \& J. Heinstrom (Eds.), New directions in information behaviour (pp. 282-300). Emerald.

Beeby, A., Fernández, M., Fox, O., Kozlova, L., Neunzig, W., Presas, M., Rodriguez, R., \& Romero, L. (2005). Investigating translation competence: Conceptual and methodological issues. Meta, 50(2), 609-619.

Berezowski, L. (2011). Jak czytać i rozumieć angielskie dokumenty sądowe w sprawach cywilnych? [How to read and understand English court documents in civil cases?] (2nd ed.). Warsaw: C.H.Beck.

Carl, M., Dragsted, B., \& Jakobsen, A. L. (2011a). A taxonomy of human translation styles. Translation Journal, 16(2), 155-168.

Carl, M., Dragsted, B., \& Jakobsen, A. L. (2011b). On the systematicity of human translation processes. Tralogy 2011. Translation Careers and Technologies: Convergence Points for the Future, Paris. http://odel.irevues.inist.fr/tralogy/ index.php?id=103

Case, D. O. (2016). Looking for information: A survey of research on information seeking, needs and behaviour ( $4^{\text {th }}$ ed.). Bingley, UK: Emerald Group Publishing.

Cattell, R. B. (1943). The description of personality: Basic traits resolved into clusters. The Journal of Abnormal and Social Psychology, 38(4).

Collin, P. H., \& Słupski, J. (1999). Słownik biznesu [The business terms dictionary]. Peter Collin Publishing. 
Cui, Y., \& Zheng, B. (2020). Consultation behaviour with online resources in EnglishChinese translation: An eye-tracking, screen-recording and retrospective study. Perspectives: Studies in Translation Theory and Practice (Online), 14 May 2020. https://doi.org/10.1080/0907676X.2020.1760899

Dragsted, B., \& Carl, M. (2013). Towards a classification of translation styles based on eye-tracking and keylogging data. Journal of Writing Research, 5(1).

EMT Expert Group. (2017). EMT Competence Framework. European Commission. https://ec.europa.eu/info/sites/info/files/emt competence fwk 2017 en web.pdf

Enríquez Raído, V. (2011). Investigating the web search behaviors of translation students: An exploratory and multiple-case study [Doctoral Dissertation]. Universitat Ramon Llull.

Enríquez Raído, V. E. (2014). Translation and web searching. New York and London: Routledge.

EUR-Lex. (n.d.). Access to European Union Law. (Web portal). https://eurlex.europa.eu/homepage.html

Eysenck, H. J. (1947). Dimensions of personality. Routledge \&Kegan Paul.

Fisiak, J. (Ed.). (2005). The New English-Polish and Polish-English Kościuszko Foundation Dictionary / Nowy słownik Fundacji Kościuszkowskiej angielskopolski $i$ polsko-angielski. New York: Kościuszko Foundation; Kraków: Universitas.

Ford, N. (1979). Study strategies, orientations and 'personal meaningfulness' in higher education. British Journal of Educational Technology, 10(2), 143-160.

Ford, N. (1986). Psychological determinants of information needs: A small-scale study of higher education students. Journal of Librarianship and Information Science, $18(1), 47-62$.

Gough, J. (2016). The patterns of interaction between professional translators and online resources. [Doctoral Dissertation, University of Surrey]. http://epubs.surrey.ac.uk/813254

Gough, J. (2017). Investigating the use of resources in the translation process. In G. Corpas Pastor \& I. Durán-Muñoz (Eds.), Trends in e-tools and resources for translators and interpreters (pp. 9-36). Leiden and Boston: Brill Rodopi.

Halder, S., Roy, A., \& Chakraborty, P. K. (2010). The influence of personality traits on information seeking behaviour of students. Malaysian Journal of Library \& Information Science, 15(1), 41-53.

Heinstrom, J. (2003). Five personality dimensions and their influence on information behaviour. Information Research, 9(1). http://www.informationr.net/ir/91/paper165.html

Heinström, J. (2005). Fast surfing, broad scanning and deep diving: The influence of personality and study approach on students' information-seeking behavior. Journal of Documentation, 61(2), 228-247.

Heinström, J. (2006). Broad exploration or precise specificity: Two basic information seeking patterns among students. Journal of the American Society for Information Science and Technology, 57(11), 1440-1450.

Heinström, J. (2010). From fear to flow: Personality and information interaction. Oxford: Chandos Publishing.

Hirci, N. (2013). Changing trends in the use of translation resources: The case of trainee translators in Slovenia. ELOPE; English Language Overseas Perspectives and Enquiries, 10(2).

House, J. (2000). Consciousness and the strategic use of aids in translation. In Sonia Tirkkonen-Condit \& R. Jääskeläinen (Eds.), Tapping and mapping the processes of translation and interpreting: Outlooks on empirical research (Vol. 37, pp. 149162). Amsterdam: John Benjamins Publishing.

Huang, J. (2018). Working styles of student translators in self-revision, other-revision and post-editing. In W. Callum \& Federico M. Federici (Eds.), Eye tracking and multidisciplinary studies on translation (pp. 145-184). Amsterdam: John Benjamins Publishing Company.

Hubscher-Davidson, S. E. (2009). Personal diversity and diverse personalities in translation: A study of individual differences. Perspectives, 17(3), 175-192.

Hvelplund, K. T. (2017). Translators' use of digital resources during translation. HERMES, 56, 71-87. https://doi.org/10.7146/hjlcb.v0i56.97205

Hvelplund, K. T. (2019). Digital resources in the translation process-attention, cognitive effort and processing flow. Perspectives, 27(4), 510-524. https://doi.org/10.1080/0907676X.2019.1575883 
International Organization for Standardization (ISO). (2015). Translation services -Requirements for translation services (ISO standard No. 17100:2015). https://www.iso.org/standard/59149.html

Jaślan, J., \& Jaślan, H. (1994). Słownik terminologii prawniczej i ekonomicznej angielsko-polski [Dictionary of legal terminology English-Polish]. Wiedza Powszechna/Lexland.

Jopek-Bosiacka, A. (2006). Przekład prawny i sadowy [Legal and court translation]. Wydawnictwo Naukowe PWN.

Jung, C. G. (1923). Psychological types or the psychology of individuation. London: Kegan Paul, Trench, Trubner \& Co. Ltd.

Kierzkowska, D., Miler, J., \& Wiśniewski, A. W. (1997). The Polish Civil Code: The law is stated as at 15th April, 1997: full text translation without commentary. Tepis Pub. House.

Kuhlthau, C. C. (1993). Seeking meaning: A process approach to library and information services. Norwood, N.J: Ablex Publishing.

Lee, K., \& Ashton, M. C. (2018). Psychometric properties of the HEXACO-100. Assessment, 25, 543-556.

Lehka-Paul, O., \& Whyatt, B. (2016). Does personality matter in translation? Interdisciplinary research into the translation process and product. Poznan Studies in Contemporary Linguistics, 52(2), 317-349.

Massey, G., \& Ehrensberger-Dow, M. (2010, October 15). Technical and instrumental competence in translation: Investigating workplace processes and practices. ILCEA (Online), 14 Traduction et Ergonomie. https://journals.openedition.org/ ilcea/1060.

Muller-Spitzer, C., Kolening, A., \& Topel, A. (2012). Online dictionary use: Key findings from an empirical research project. In S. Granger \& M. Paquot (Eds.), Electronic Lexicography (pp. 425-457). Oxford University Press.

Murray, H. A. (1938). Explorations in Personality: A clinical and experimental study of fifty men of college age. New York: Oxford University Press.

Myrczek-Kadłubicka, E. (2013a). Dictionary of Law Terms (3rd ed.). Warsaw: C.H. Beck.

Myrczek-Kadłubicka, E. (2013b). Lexicon of law terms. Warsaw: C. H. Beck.

NAATI (National Accreditation Authority for Translators and Interpreters). (n.d.). Skills and competencies for translating. https://www.naati.com.au/informationguides/descriptors-for-translating/

O’Brien, H. L., Dickinson, R., \& Askin, N. (2017). A scoping review of individual differences in information seeking behavior and retrieval research between 2000 and 2015. Library \& Information Science Research, 39(3), 244-254.

Olalla-Soler, C. (2018). Using electronic information resources to solve cultural translation problems. Journal of Documentation, 74(6), 1293-1317. https://doi.org/10.1108/JD-02-2018-0033

Ożga, E. (2009). The great dictionary of law and economics Polish-English EnglishPolish. Warsaw: C.H. Beck.

PACTE. (2017). PACTE translation competence model. A holistic, dynamic model of translation competence. In A. H. Albir (Ed.), Researching Translation Competence by PACTE Group (pp. 35-41). Amsterdam: John Benjamins.

Pedrazzini, L., \& Nava, A. (2012). Individual differences in dictionary strategy use. In M. Pawlak (Ed.), New perspectives on individual differences in language learning and teaching (pp. 319-334). Springer. https://doi.org/10.1007/978-3-642-20850820

Pinto, María, García-Marco, J., Granell, X., \& Sales, D. (2014). Assessing information competences of translation and interpreting trainees: A study of proficiency at Spanish universities using the InfoliTrans Test. Aslib Journal of Information Management, 66(1), 77-95.

Pinto, María, \& Sales, D. (2007). A research case study for user-centred information literacy instruction: Information behaviour of translation trainees. Journal of Information Science, 33(5), 531-550.

Pinto, María, \& Sales, D. (2008). Towards user-centred information literacy instruction in translation: The view of trainers. The Interpreter and Translator Trainer, 2(1), 47-74. https://doi.org/10.1080/1750399X.2008.10798766

Sales, D., \& Pinto, M. (2011). The professional translator and information literacy: Perceptions and needs. Journal of Librarianship and Information Science, 43(4), 246-260. 
Shih, C. Y. (2019). A quest for web search optimisation: An evidence-based approach to trainee translators' behaviour. Perspectives, 27(6), 908-923. https://doi.org/10.1080/0907676X.2019.1579847

Sycz-Opoń, J. (2019). Information-seeking behaviour of translation students at the University of Silesia during legal translation-an empirical investigation. The Interpreter and Translator Trainer, 13(2), 152-176.

Tarp, S. (2007). Lexicography in the information age. Lexikos, 17, 170-179.

Tidwell, M., \& Sias, P. (2005). Personality and information seeking: Understanding how traits influence information-seeking behaviors. The Journal of Business Communication, 42(1), 51-77. https://doi.org/10.1177/0021943604272028

Tirkkonen-Condit, S. (2005). The monitor model revisited: Evidence from process research. Meta: Journal Des Traducteurs/Meta: Translators'Journal, 50(2), 405414.

White, M. D., Matteson, M., \& Abels, E. G. (2008). Beyond dictionaries: Understanding information behavior of professional translators. Journal of Documentation, 64(4), 576-601.

Wilson, T. D. (2000). Human information behavior. Informing Science, 3(2), 49-56.

Zapata, J. (2016). Investigating translator-information interaction: A case study on the use of the prototype biconcordancer tool integrated in CASMACAT. In M. Carl, S. Bangalore \& M. Schaeffer, New Directions in Empirical Translation Process Research (pp. 135-152). Springer.

Zhang, L., \& Sternberg, R. J. (2005). A threefold model of intellectual styles. Educational Psychology Review, 17(1), 1-53. 
Appendix 1: Excerpt from the Observation protocol (translated from Polish)

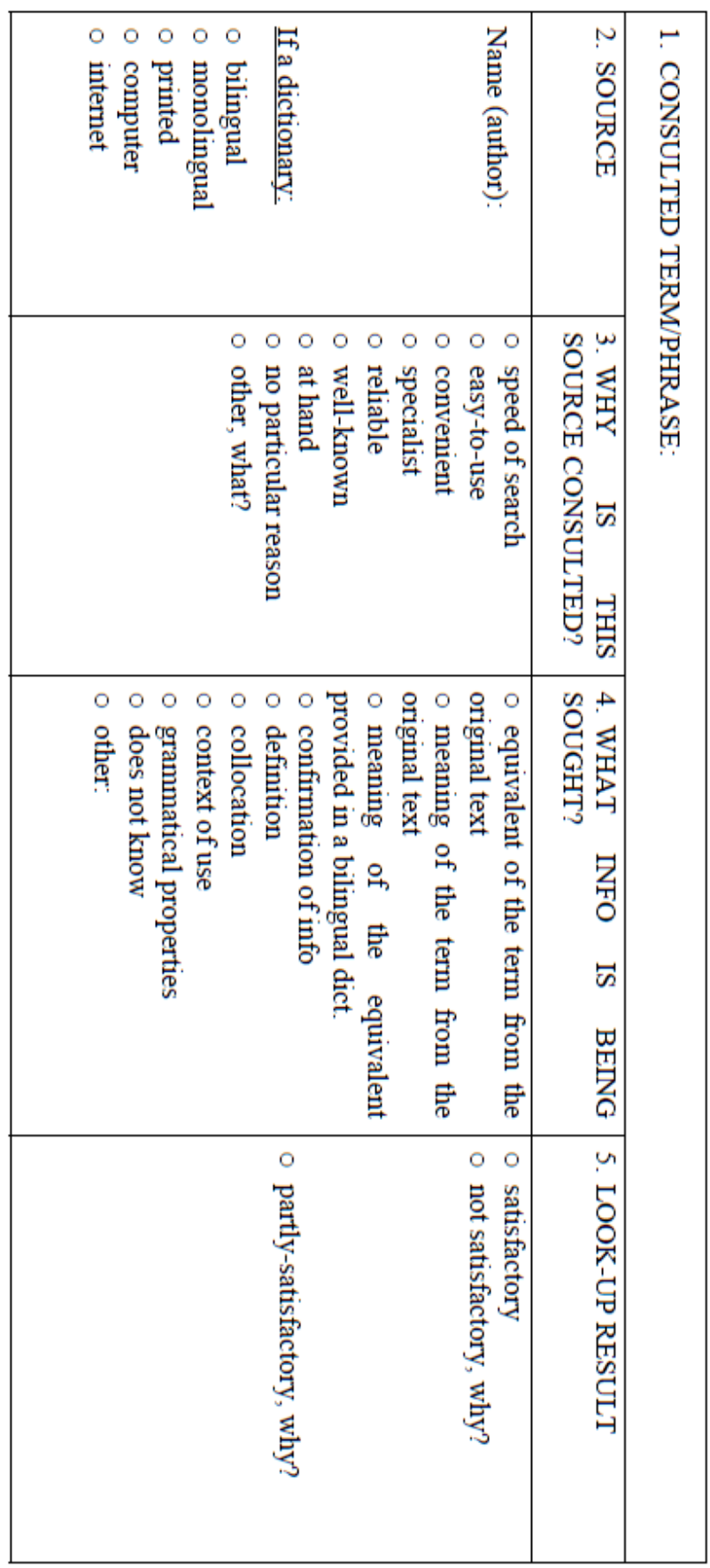


Appendix 2: Look-ups in printed versus electronic sources per participant




Appendix 3: Look-up rate in printed versus electronic dictionaries per participant

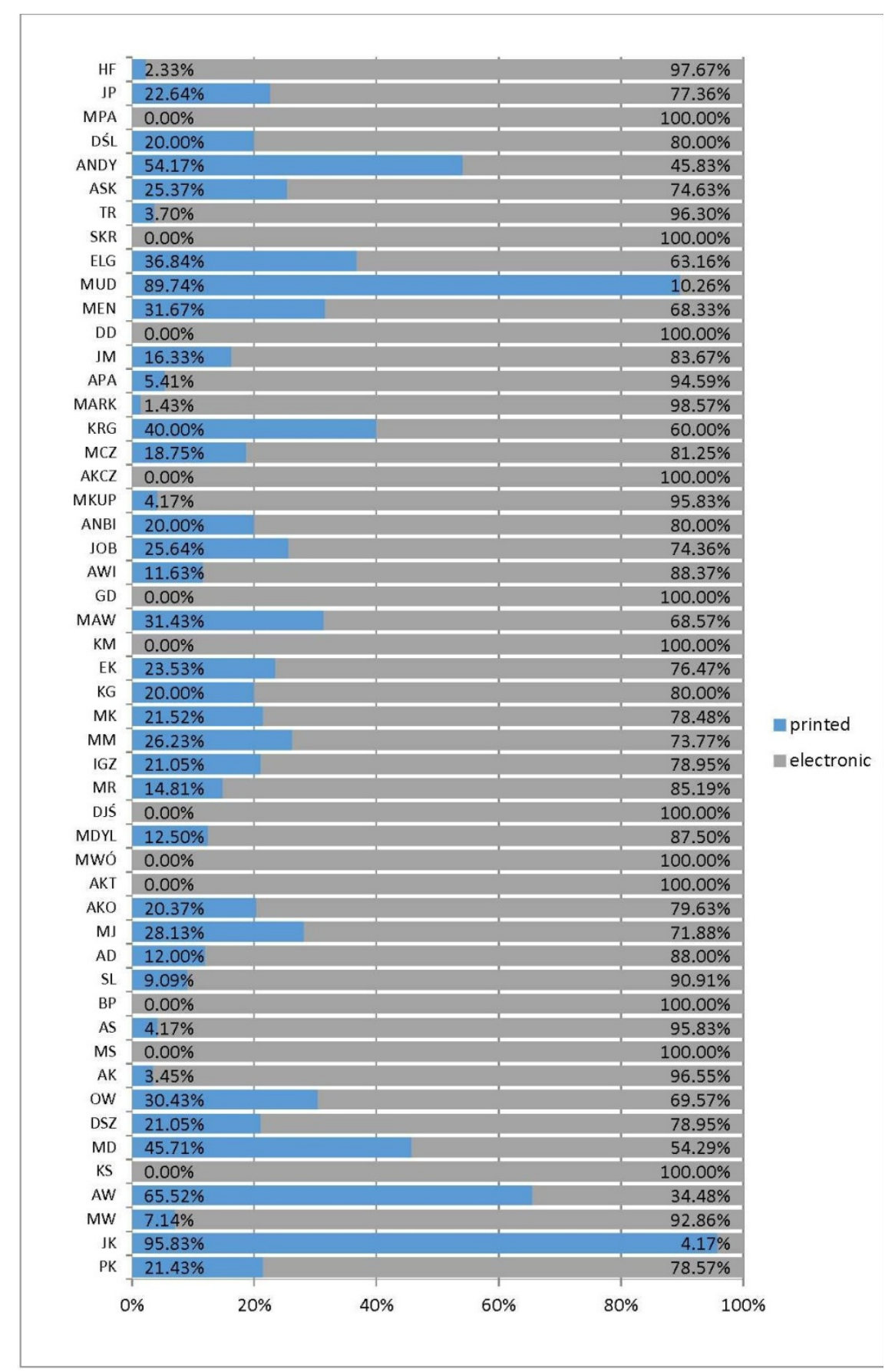


Appendix 4: Look-ups in bilingual versus monolingual dictionaries per participant

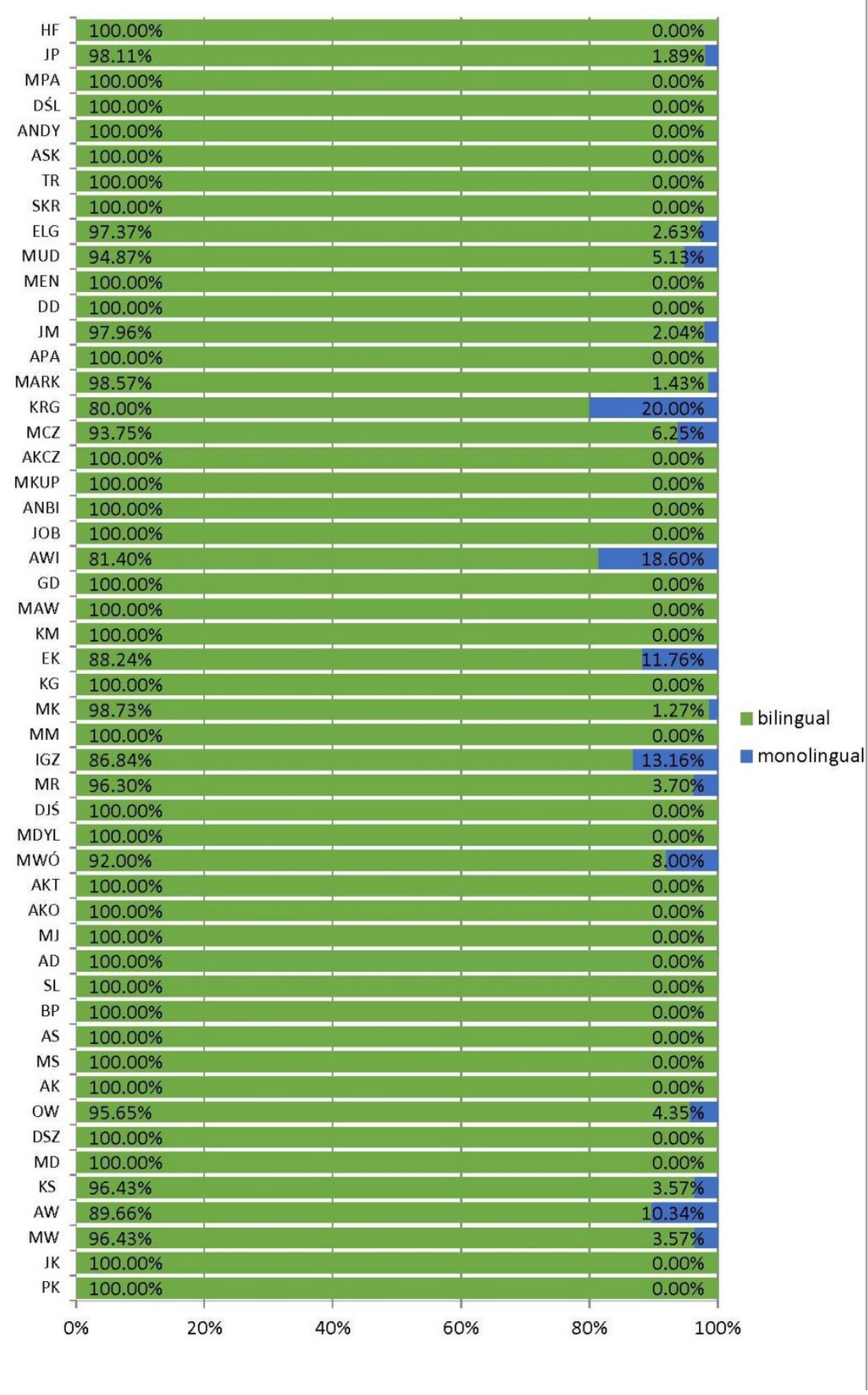




\section{Appendix 5: Look-ups in official versus unofficial sources per participant}

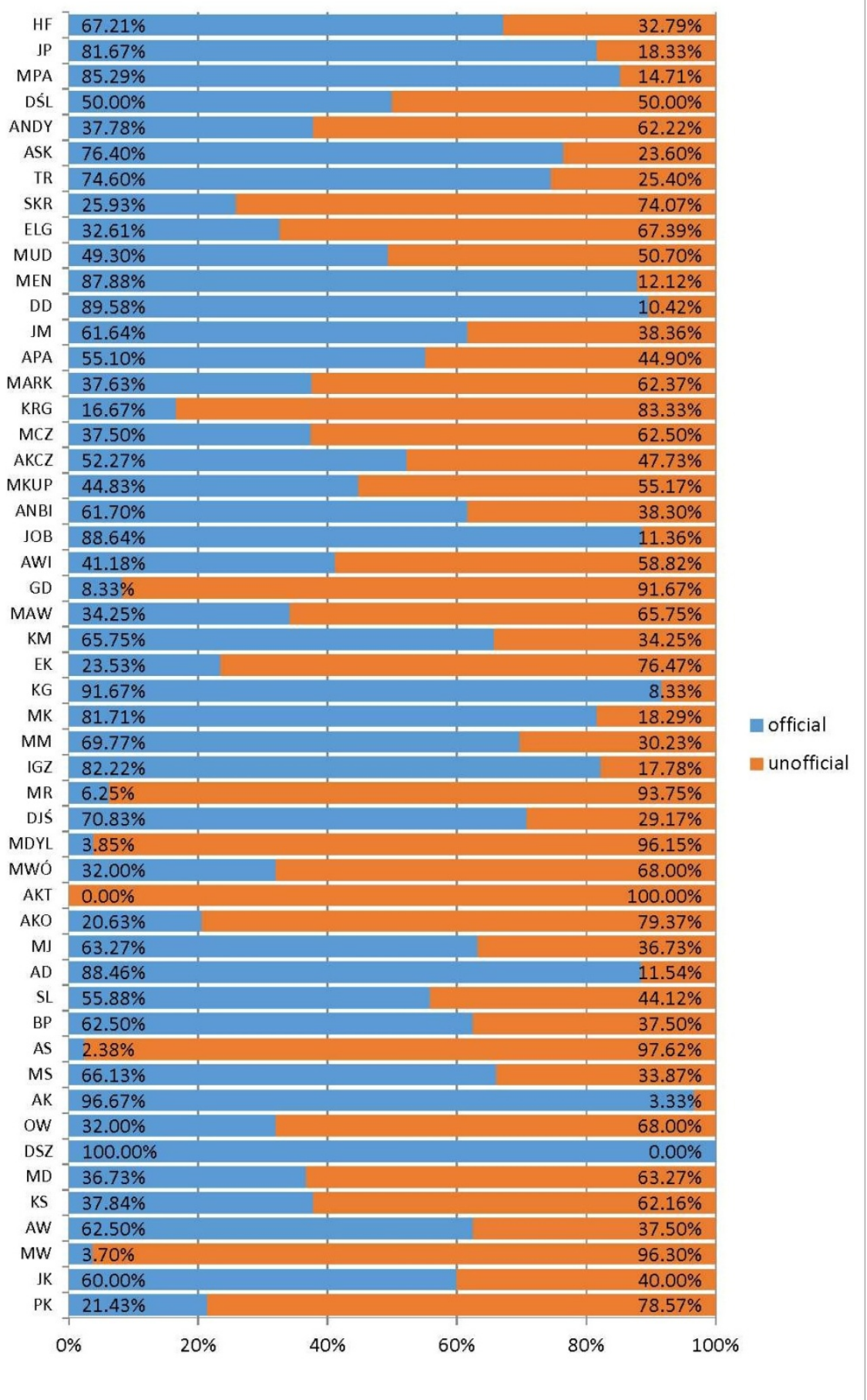


Appendix 6: Look-ups in official versus unofficial dictionaries per participant

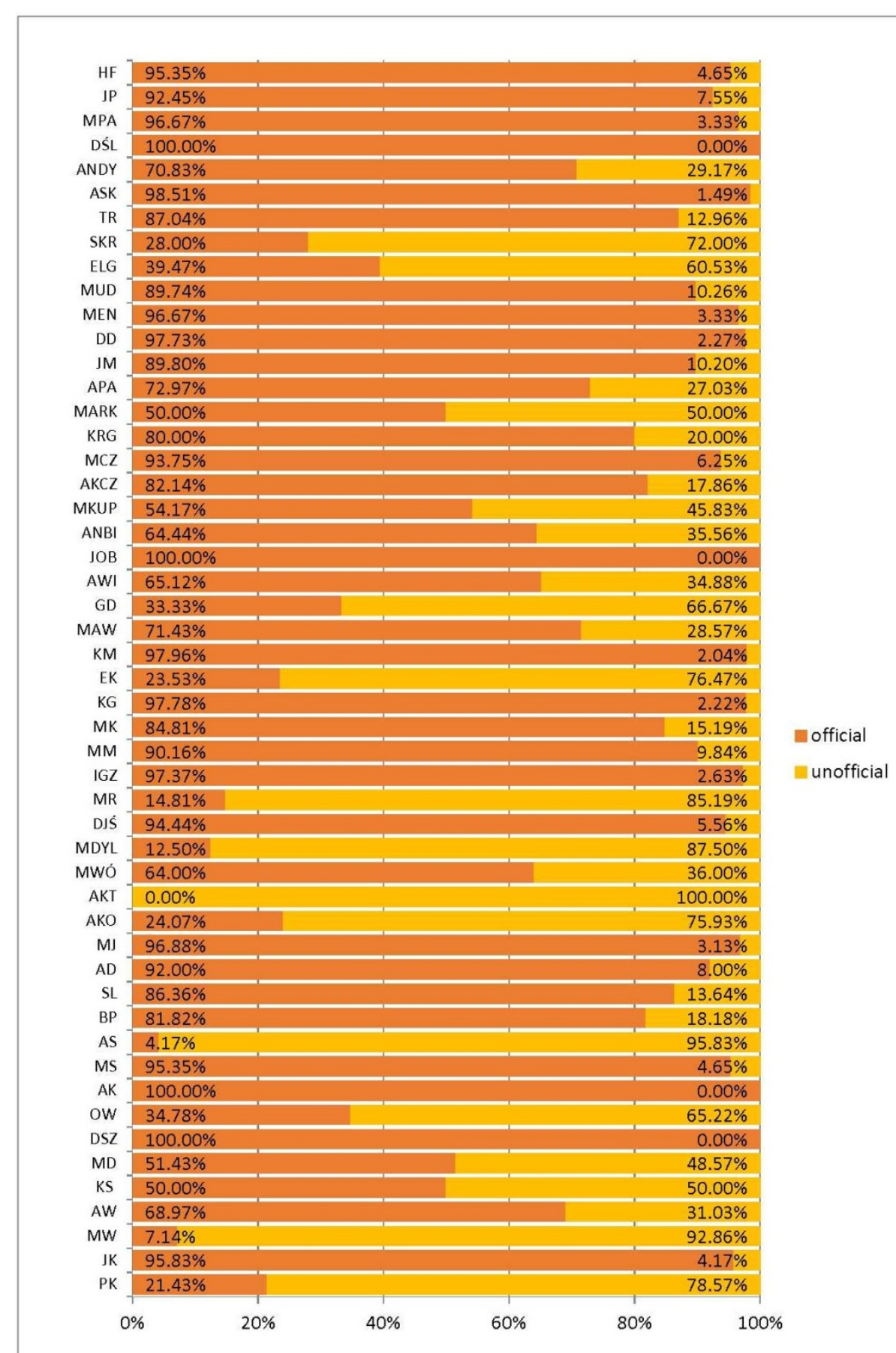


Appendix 7: Source diversity (the number of different sources used by each participant during the entire experiment session)

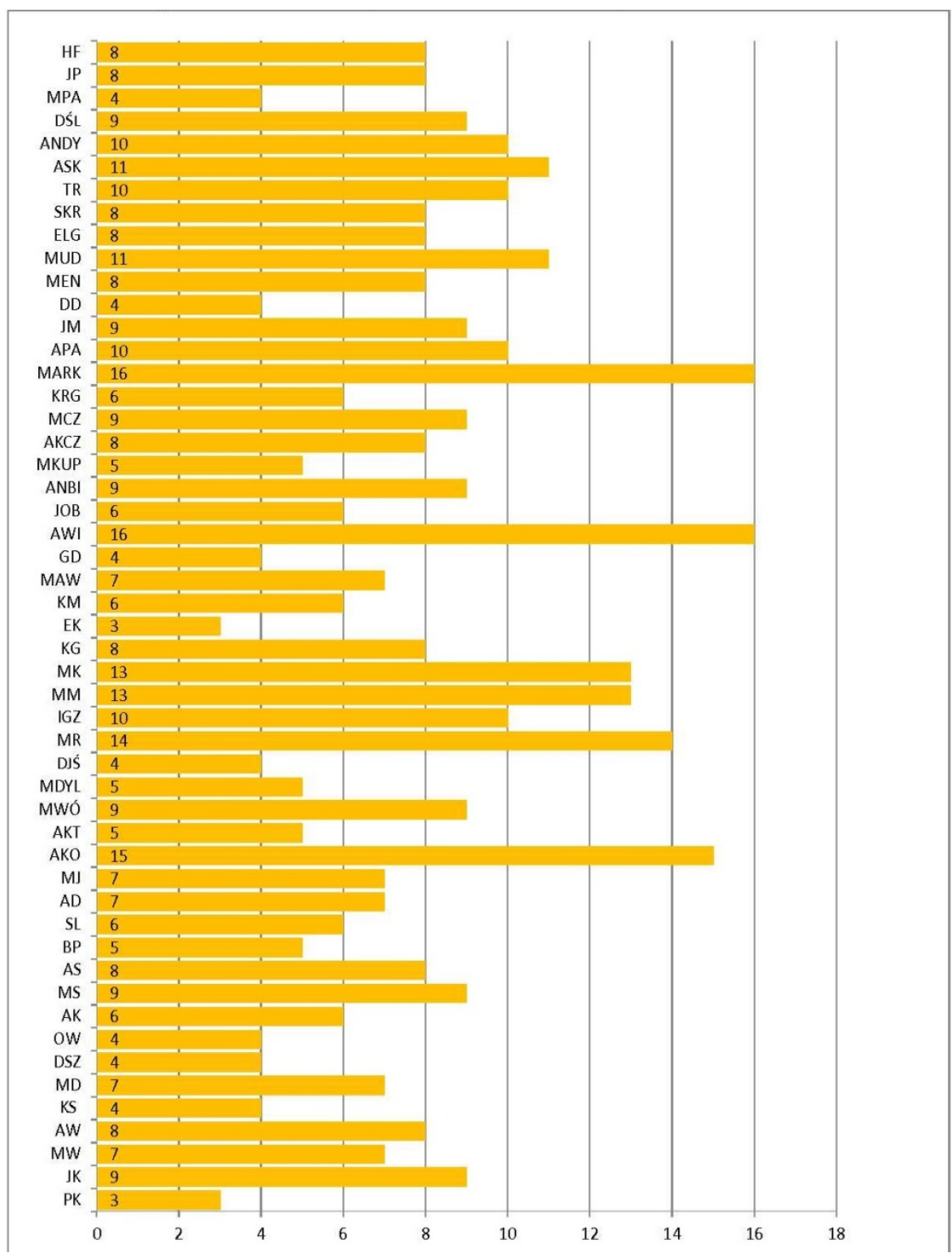




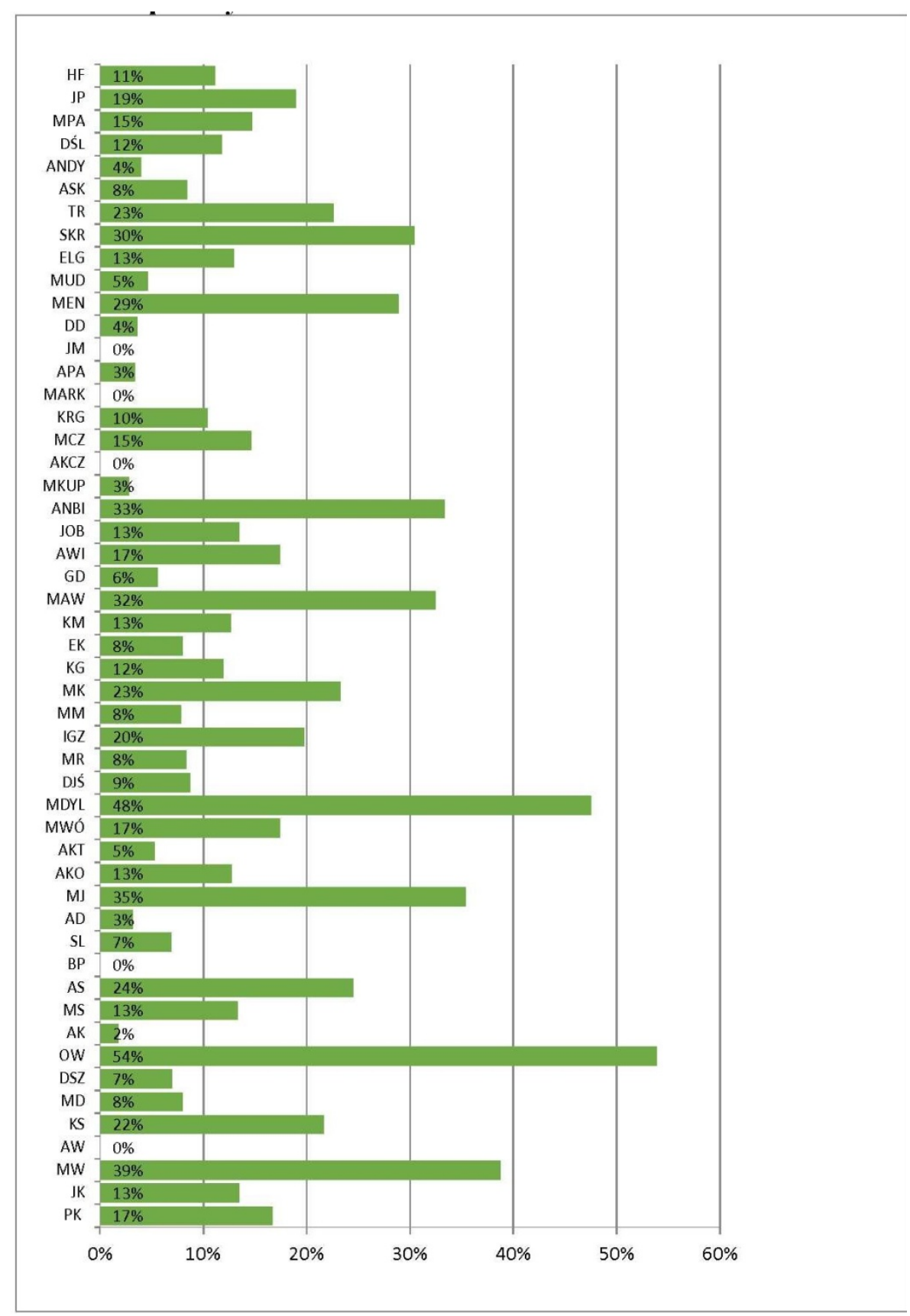


Appendix 9: Number of searches conducted during entire translation session

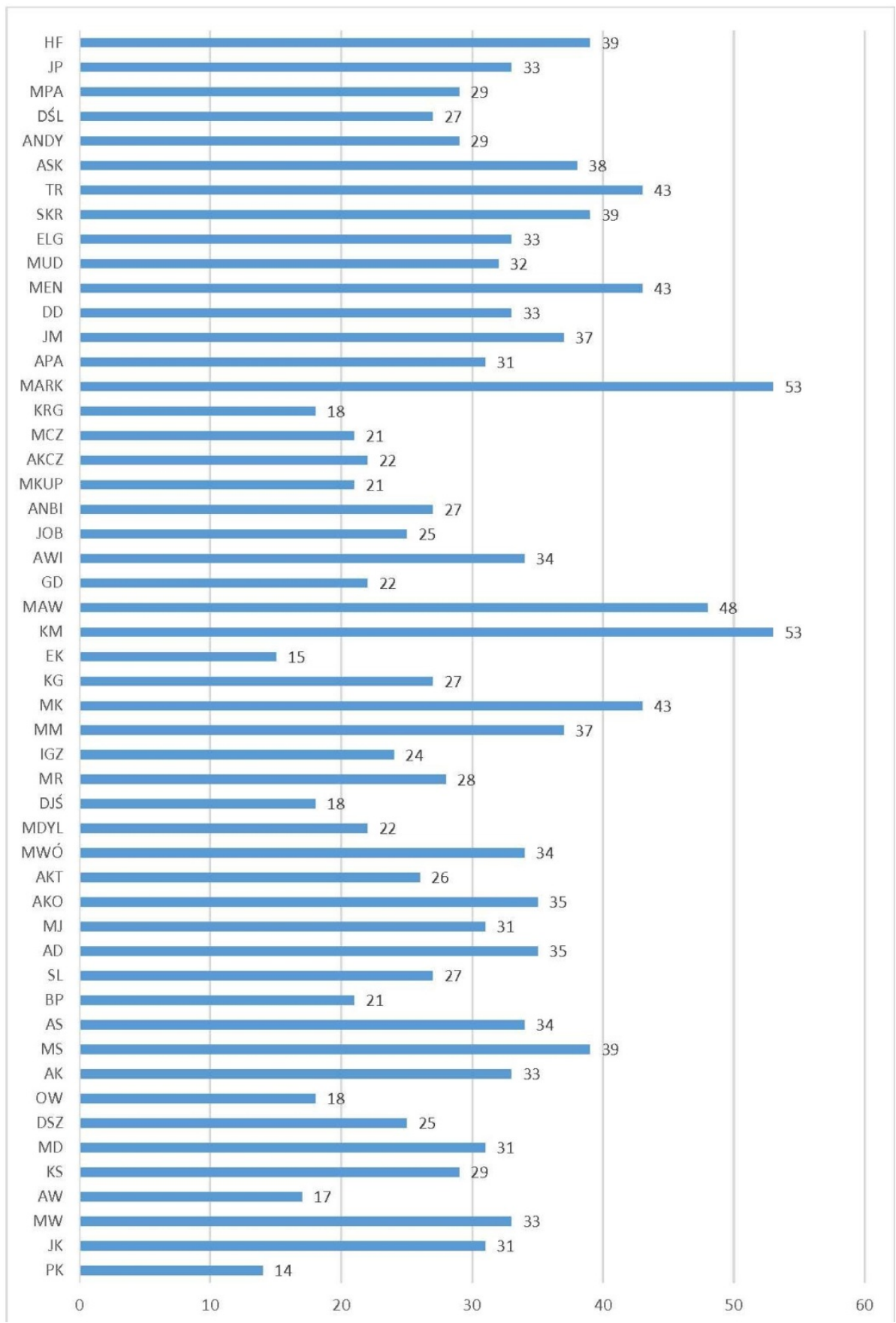




\section{Appendix 10: Percent of 1-look-up searches in total searches}

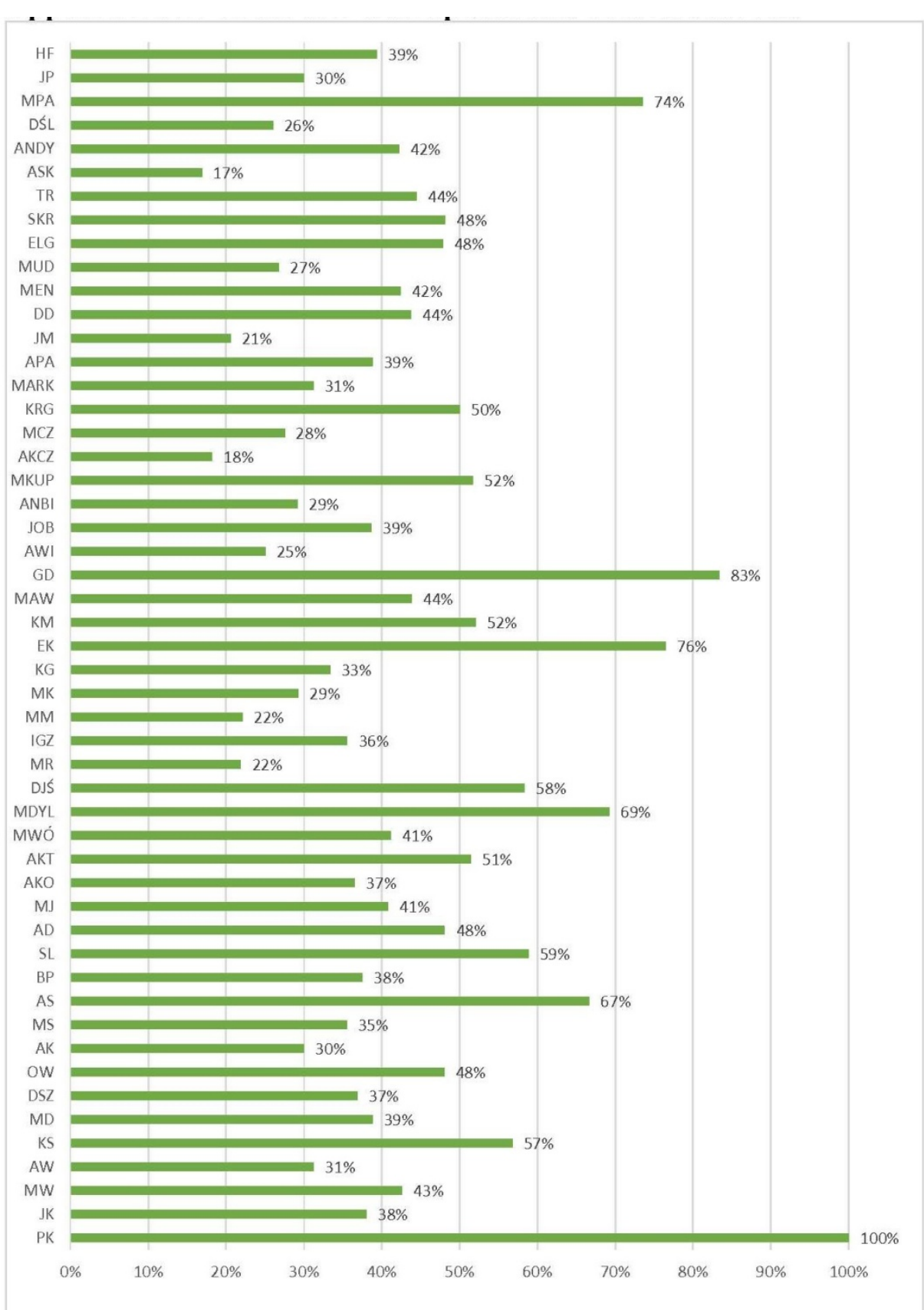


Appendix 11: Length of searches (No. of look-ups in a search)

\begin{tabular}{|c|c|c|c|c|c|c|c|c|c|c|c|c|}
\hline Participants & $\begin{array}{l}\text { Total look- } \\
\text { ups }\end{array}$ & $\begin{array}{l}1 \text { look- } \\
\text { up }\end{array}$ & $\begin{array}{l}2 \text { look- } \\
\text { ups }\end{array}$ & $\begin{array}{l}3 \text { look- } \\
\text { ups }\end{array}$ & $\begin{array}{l}4 \text { look- } \\
\text { ups }\end{array}$ & $\begin{array}{l}5 \text { look- } \\
\text { ups }\end{array}$ & $\begin{array}{l}6 \text { look- } \\
\text { ups }\end{array}$ & $\begin{array}{l}7 \text { look- } \\
\text { ups }\end{array}$ & $\begin{array}{l}8 \text { look- } \\
\text { ups }\end{array}$ & $\begin{array}{l}9 \text { look- } \\
\text { ups }\end{array}$ & $\begin{array}{l}\text { 10- look- } \\
\text { ups }\end{array}$ & $\begin{array}{l}11 \text { look- } \\
\text { ups }\end{array}$ \\
\hline PK & 14 & 14 & & & & & & & & & & \\
\hline JK & 50 & 19 & 5 & 7 & & & & & & & & \\
\hline MW & 54 & 23 & 5 & 3 & 1 & & & & 1 & & & \\
\hline AW & 32 & 10 & 4 & & 1 & 2 & & & & & & \\
\hline KS & 37 & 21 & 8 & & & & & & & & & \\
\hline MD & 49 & 19 & 8 & 2 & 2 & & & & & & & \\
\hline DSZ & 38 & 14 & 9 & 2 & & & & & & & & \\
\hline OW & 25 & 12 & 5 & 1 & & & & & & & & \\
\hline AK & 60 & 18 & 7 & 6 & & 2 & & & & & & \\
\hline MS & 62 & 22 & 12 & 4 & 1 & & & & & & & \\
\hline AS & 42 & 28 & 4 & 2 & & & & & & & & \\
\hline BP & 32 & 12 & 7 & 2 & & & & & & & & \\
\hline$S L$ & 34 & 20 & 7 & & & & & & & & & \\
\hline$A D$ & 52 & 25 & 6 & 2 & 1 & 1 & & & & & & \\
\hline MJ & 49 & 20 & 6 & 3 & 2 & & & & & & & \\
\hline AKO & 63 & 23 & 7 & 1 & 1 & 1 & 1 & & 1 & & & \\
\hline AKT & 35 & 18 & 7 & 1 & & & & & & & & \\
\hline MWÓ & 51 & 21 & 9 & 4 & & & & & & & & \\
\hline MDYL & 26 & 18 & 4 & & & & & & & & & \\
\hline DJŚ & 24 & 14 & 2 & 2 & & & & & & & & \\
\hline MR & 64 & 14 & 5 & 2 & 4 & 1 & 1 & 1 & & & & \\
\hline IGZ & 45 & 16 & 4 & 1 & & 1 & 1 & 1 & & & & \\
\hline $\mathrm{MM}$ & 86 & 19 & 5 & 5 & 4 & 3 & & & & & & 1 \\
\hline MK & 82 & 24 & 7 & 7 & 4 & & & 1 & & & & \\
\hline KG & 48 & 16 & 6 & 2 & 2 & & 1 & & & & & \\
\hline EK & 17 & 13 & 2 & & & & & & & & & \\
\hline KM & 73 & 38 & 11 & 3 & 1 & & & & & & & \\
\hline MAW & 73 & 32 & 11 & 2 & 2 & 1 & & & & & & \\
\hline GD & 24 & 20 & 2 & & & & & & & & & \\
\hline AWI & 72 & 18 & 6 & 4 & 3 & 1 & 1 & 1 & & & & \\
\hline JOB & 44 & 17 & 3 & 2 & & 3 & & & & & & \\
\hline ANBI & 48 & 14 & 9 & 3 & & & & 1 & & & & \\
\hline MKUP & 29 & 15 & 4 & 2 & & & & & & & & \\
\hline AKCZ & 44 & 8 & 8 & 4 & 2 & & & & & & & \\
\hline MCZ & 40 & 11 & 3 & 5 & 2 & & & & & & & \\
\hline KRG & 24 & 12 & 6 & & & & & & & & & \\
\hline MARK & 93 & 29 & 13 & 8 & 1 & 2 & & & & & & \\
\hline APA & 49 & 19 & 7 & 4 & 1 & & & & & & & \\
\hline JM & 73 & 15 & 13 & 4 & 5 & & & & & & & \\
\hline DD & 48 & 21 & 9 & 3 & & & & & & & & \\
\hline MEN & 66 & 28 & 9 & 4 & 2 & & & & & & & \\
\hline MUD & 71 & 19 & 6 & & 2 & 2 & 2 & & & & 1 & \\
\hline ELG & 46 & 22 & 9 & 2 & & & & & & & & \\
\hline SKR & 54 & 26 & 11 & 2 & & & & & & & & \\
\hline TR & 63 & 28 & 12 & 1 & 2 & & & & & & & \\
\hline ASK & 89 & 15 & 11 & 5 & 2 & 3 & 1 & & 1 & & & \\
\hline ANDY & 45 & 19 & 7 & 2 & & & 1 & & & & & \\
\hline DŚL & 50 & 13 & 7 & 5 & 2 & & & & & & & \\
\hline MPA & 34 & 25 & 3 & 1 & & & & & & & & \\
\hline$J P$ & 60 & 18 & 7 & 5 & 2 & 1 & & & & & & \\
\hline $\mathrm{HF}$ & 61 & 24 & 8 & 7 & & & & & & & & \\
\hline
\end{tabular}

